\title{
Metabolic syndrome and depressive symptoms among Japanese men and women
}

\author{
Yasumi Kimura $\cdot$ Yumi Matsushita $\cdot$ \\ Akiko Nanri · Tetsuya Mizoue
}

Received: 11 March 2010/Accepted: 13 January 2011/Published online: 15 February 2011

(C) The Japanese Society for Hygiene 2011

\begin{abstract}
Objectives Evidence is limited on the relation between metabolic syndrome and depressive symptoms. The aim of this cross-sectional study was to investigate the association between metabolic syndrome and depressive symptoms in a Japanese working population.

Methods The study subjects comprised 458 municipal employees (age range 21-67 years) from two municipal offices in Japan. A modified version of the criteria of the National Cholesterol Education Program Adult Treatment Panel III was used to define metabolic syndrome. Depressive symptoms were assessed using the Center for Epidemiologic Studies Depression (CES_D) scale.

Results Depressive symptoms (CES_D $\geq 16$ ) in both the male and female subjects were not significantly associated with metabolic syndrome nor with each component of metabolic syndrome. In men, high fasting glucose was associated with increased prevalence of severe depressive state (CES_D $\geq 23$ ).

Conclusions Metabolic syndrome may not be associated with depressive status among Japanese employees.
\end{abstract}

Keywords Metabolic syndrome - Depressive symptoms · CES_D · NCEP-ATP III · Hyperglycemia

Y. Kimura $(\bowtie)$

Department of Nutrition and Life Science,

Faculty of Life Science and Biotechnology,

Fukuyama University, 1 Gakuencho, Fukuyama,

Hiroshima 729-0292, Japan

e-mail: kimura@fubac.fukuyama-u.ac.jp

Y. Matsushita · A. Nanri - T. Mizoue

Department of Epidemiology and International Health,

International Clinical Research Center,

National Center for Global Health and Medicine,

Tokyo, Japan

\section{Introduction}

Metabolic syndrome is a clustering of risk factors for cardiovascular diseases (CVD) [1] and type 2 diabetes [2]. Essential components of metabolic syndrome are glucose intolerance, hypertension, dyslipidemia, and central obesity, although there are variations in the criteria defining the syndrome [3]. Depressive status has been linked to metabolic abnormalities, such as abdominal obesity, high blood pressure, and insulin resistance [4-6]. Moreover, several studies have examined depressive state in relation to metabolic syndrome. In two cross-sectional studies, metabolic syndrome was significantly associated with a higher prevalence of depression in young U.S. women [7] and in Japanese men [8]. Similarly, metabolic syndrome was found to be a significant predictor of depression in prospective studies of middle-aged British adults [9] and Japanese male employees [10], although no such association was observed in large cross-sectional studies of Finnish young adults [11] and Norwegian adults [12]. Among Japanese populations, only two studies (one crosssectional study [8] and one cohort study [10] in the same setting) have reported epidemiologic data on this subject, but both included data for men only. In the study reported here, we examined the association between metabolic syndrome and its components and depressive symptoms in Japanese men and women.

\section{Methods}

Details of the study procedure have been described elsewhere [13]. In brief, this cross-sectional study was based on data collected during a health survey conducted in July and November 2006 among employees of two municipal 
offices in northeastern Kyushu, Japan. All employees were invited to participate in the survey $(n=601)$. Of these 601 employees, 547 (response rate 91\%), aged 21-67 years, agreed to participate. Data on anthropometric measurements, blood parameters (from venous blood sample), and lifestyle (by questionnaire) were obtained. After the exclusion of those subjects with missing information, 458 Japanese subjects ( 285 men and 173 women) remained for analysis. The protocol of the study was approved by the Ethics Committee of the National Center for Global Health and Medicine, and written informed consent was obtained from each subject.

Metabolic syndrome and metabolic risk factors were defined according to a modified version of the criteria of the National Cholesterol Education Program's Adults Treatment Panel III (NCEP-ATP III) [14]. Since the survey was conducted before the implementation of the medical examination for metabolic syndrome, waist circumference was not measured. We thus used body mass index (BMI) instead, which is highly correlated with waist circumference ( $r=0.874, p=0.0001)$ [15] and has been used in epidemiologic studies lacking waist circumference data.

Men having three or more of the following criteria were defined as having metabolic syndrome [16] and, due to the low number of women showing high triglyceride $(n=2)$, women having two or more of the same criteria were defined as having semi-metabolic syndrome: (1) obesity: BMI $\geq 25 \mathrm{~kg} / \mathrm{m}^{2}$; (2) high triglycerides: triglycerides $\geq 150 \mathrm{mg} / \mathrm{dl}$; (3) low high-density lipoprotein (HDL) cholesterol: $<40 \mathrm{mg} / \mathrm{dl}$ in men, $<50 \mathrm{mg} / \mathrm{dl}$ in women; (4) high blood pressure: systolic blood pressure $\geq 130 \mathrm{mmHg}$ or diastolic blood pressure $\geq 85 \mathrm{mmHg}$; (5) high fasting glucose (overnight fasting): $\geq 100 \mathrm{mg} / \mathrm{dl}$. Subjects under the care of a physician due to hyperlipidemia, hypertension, or diabetes were deemed as having the respective risk factors, regardless of the biochemical values and medication status. Depressive symptoms were assessed using a Japanese version [17] of the Center for Epidemiologic Studies Depression (CES_D) scale [18]. Depressive symptoms were defined as a CES_D score $\geq 16$ and severe depressive state was defined as a CES_D score $\geq 23$. The modified Brief Job Stress Questionnaire, in which a higher score indicates greater stress, was used to assess job stress score [19].

Separate analyses were performed on the data for men and women. The differences between the two groups for continuous variables were assessed by an independent $t$ test and those for categorical variables were assessed by the chi-square test. Logistic regression analysis was used to assess the association between depressive symptoms and metabolic syndrome and each of its components.

We performed three types of analysis: (1) crude model without any adjustment, (2) multivariate model adjusted for marital status and job stress score in men and occupational physical activity and job stress score in women (Model 1), and (3) multivariate model adjusted for age, workplace, marital status, job stress score, occupational physical activity, leisure-time physical activity, current smoking, current alcohol drinking, and total energy intake (Model 2). We included these variables in the model based on their known or potential relations either to depressive symptoms or to obesity. Statistical significance was declared when $p$ was $<0.05$. All statistical analyses were performed with SAS ver. 9.1 (SAS Institute, Cary, NC).

\section{Results}

The prevalence of depressive symptoms (CES_D score $\geq 16$ ) and severe depressive symptoms (CES_D score $\geq 23$ ) were 36.5 and $14.0 \%$ in men and 37.6 and $14.5 \%$ in women, respectively. Among the study subjects, $17.2 \%$ of the men had metabolic syndrome ( $\geq 3$ components), whereas $11.0 \%$ of women had semi-metabolic syndrome ( $\geq 2$ components). As shown in Table 1, compared to subjects without depressive symptoms, those of both sexes with depressive symptoms were more likely to have high job stress score, be unmarried (men only), and be engaged in occupational physical activity (women only), and compared to subjects without severe depressive symptoms of both sexes, those with severe depressive symptoms were more likely to have high job stress score, be unmarried (men only), not be engaged in leisure-time physical activity (men only), and be engaged in occupational physical activity (women only). There were no material differences between the two groups for BMI, triglycerides, HDL cholesterol, systolic blood pressure, diastolic blood pressure, and fasting glucose. A relatively strong correlation $(r=>0.4)$ was observed between CES_D and the job stress score $(r=0.51, p<0.0001$ in men; $r=0.41$, $p=0.0001$ in women), between fasting glucose and age $(r=0.43, p=0.0001$ in men; $r=0.43, p=0.0001$ in women), and between diastolic blood pressure and age $(r=0.46, p=0.0001$ in men; $r=0.20, p=0.007$ in women).

As Table 2 shows, no significant association was observed between depressive symptoms and metabolic syndrome and each of its components in both men and women. There were no statistically significant interactions for depressive symptoms between metabolic syndrome and other independent variables. For severe depressive symptoms (CES_D score $\geq 23 ; n=40$ ), a positive association with fasting hyperglycemia was observed in men; crude odds ratio (95\% confidence interval) and adjusted odds ratio (95\% confidence interval) for Models 1 and 2 were 1.39 (0.68-2.86), 2.05 (0.91-4.63), and 2.66 (1.05-6.72), respectively. 


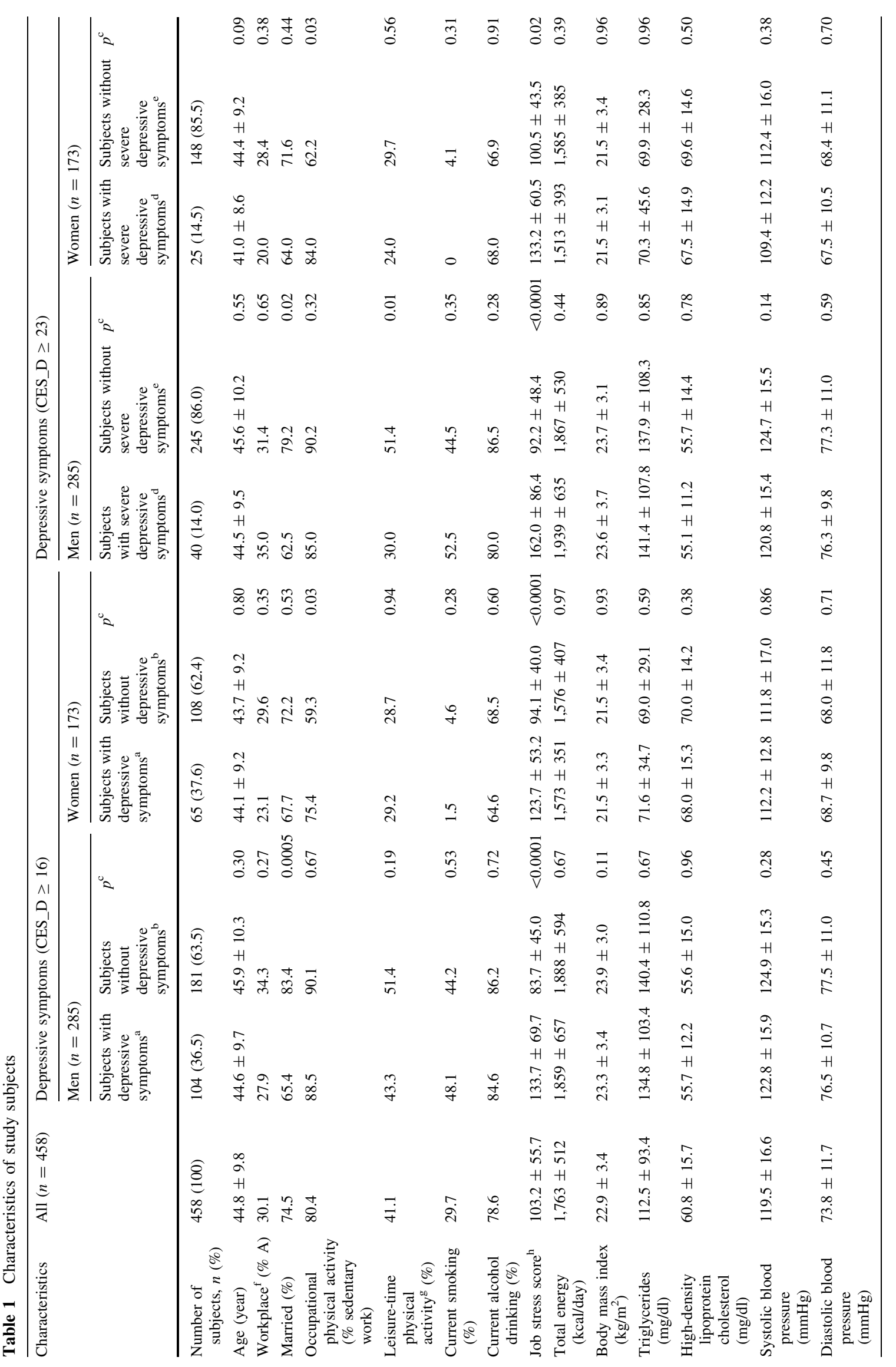




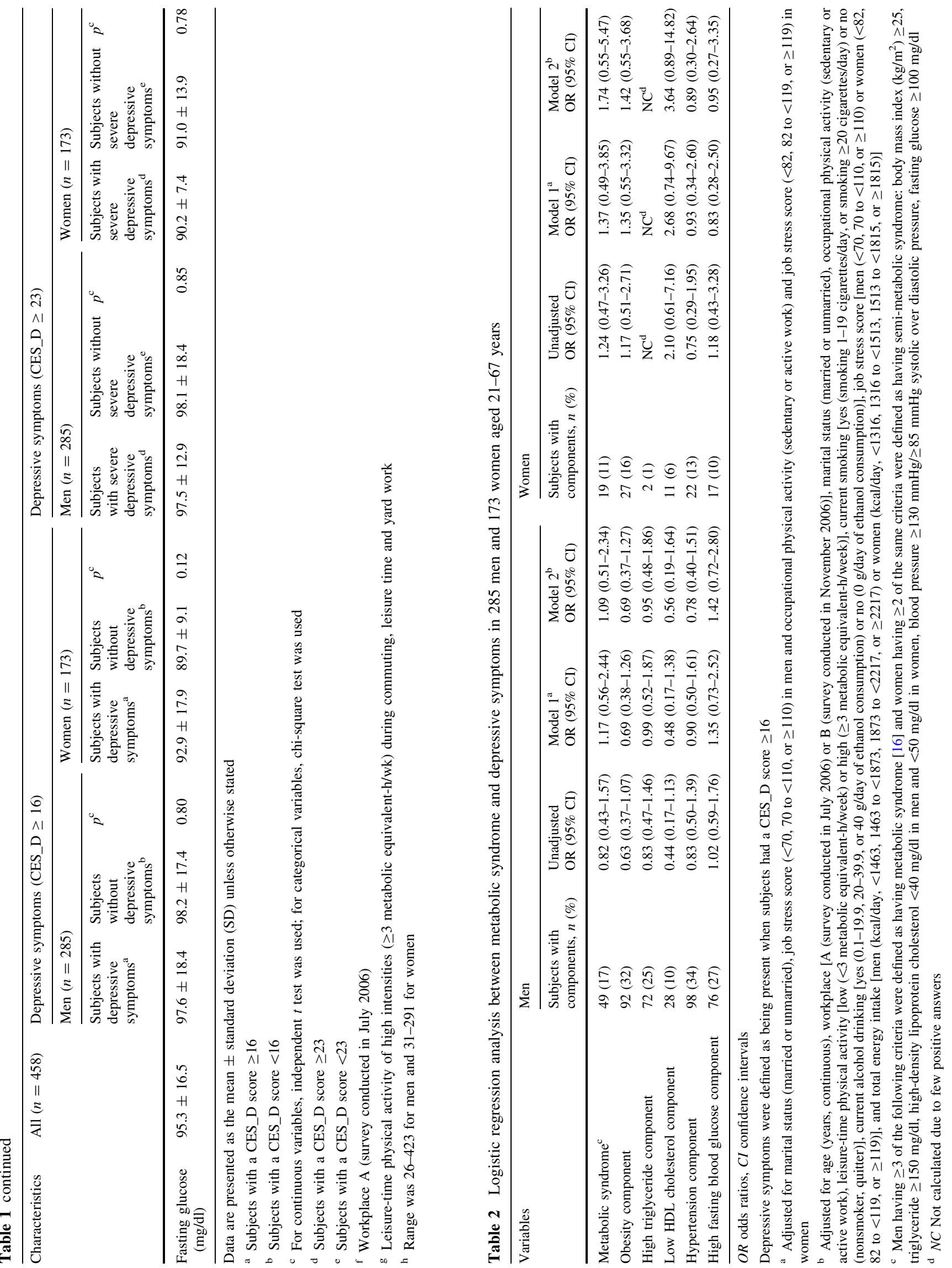




\section{Discussion}

The results of this study among a Japanese working population did not reveal any relation between depressive symptoms and metabolic syndrome in both men and women. There was also no association between depressive symptoms and each component of metabolic syndrome, with the exception of a positive association between fasting hyperglycemia and severe depressive symptoms (CES_D score $\geq 23)$. The prevalence $(36.5 \%$ in men, $37.6 \%$ in women) of depressive symptoms (CES_D score $\geq 16$ ) among our study population is much higher than that reported in studies on Western populations but is similar to that reported in a previous large-scale study of Japanese workers (38.3\% in men, $39.8 \%$ in women) [20].

Metabolic syndrome has been shown to be associated with depressive symptoms in studies performed in Western countries [7, 9, 21-26] and Japan [8, 10], although the association is not entirely consistent $[11,12]$. This inconsistency could be ascribed to the difference in the criteria of depressive symptoms and metabolic syndrome across studies. Many earlier studies [7, 9, 11, 24, 25] used NCEPATP criteria, which we also adopted in our study, whereas others used the criteria of the International Diabetes Foundation (IDF) [8, 10, 12].

The CES_D scale has been developed for epidemiological studies of depression, and the reliability of its Japanese version has been confirmed [17]. The CES_D scale was used in our study, as well as in a number of previous studies [22, 25] to assess depressive symptoms; other studies have used different criteria, including the Profile of Mood States (POMS) [8, 10] and Hospital Anxiety and Depression Scale (HADS_D) [21, 27].

Although previous Japanese studies performed in the workplace setting $[8,10]$ reported a positive relationship between metabolic syndrome and depression, we did not detect such an association in our study. This inconsistency with earlier results needs to be discussed from a methodological point of view. These two earlier studies employed different diagnostic criteria for metabolic syndrome (IDF) from those used in our study (NCEP-ATP III). However, the final proportion of all participants with metabolic syndrome in one of the earlier studies (cross-sectional study by Takeuchi et al. [8]) does not differ greatly from that found in our study (12.2 vs. $17.2 \%)$. However, there is a large difference between these studies in the proportion of men with depression. The proportion of subjects with mild depression and depression were 6.9 and $0.7 \%$, respectively, in Takeuchi et al.'s study [8], whereas the proportion of subjects with depression (defined as CES_D $\geq 16$ ) and severe depression (defined as CES_D $\geq 23$ ) was 36.5 and $14.0 \%$, respectively, in our study. This difference is likely due to the different depression scales used, and these considerable differences in the prevalence of depression may account, at least in part, for the inconsistent findings among Japanese studies.

We found a positive association between severe depressive symptoms (CES_D score $\geq 23$ ) and fasting hyperglycemia in men after adjusting for potential confounders. Prospective studies in Italy [28] and Spain [29] have shown that diabetes at baseline is associated with an increased risk of developing depressive symptoms. Moreover, in a meta-analysis involving 42 cross-sectional studies, subjects with diabetes had a twofold increased prevalence of depressive symptoms than subjects without diabetes [30]. Our finding is in line with these results. However, epidemiologic data are not entirely consistent. In a retrospective cohort study performed in Canada [31], diabetes was not associated with risk of depression, a finding which the authors ascribed to undiagnosed diabetes cases. In a U.S. prospective study [32], treated diabetes predicted an increased risk of depressive symptoms, but impaired fasting glucose and untreated diabetes were associated with a lower, rather than higher, risk of developing depressive symptoms. The inconsistency in the results among studies may thus be due to differences not only in the depression scales and diabetes criteria but also in other factors, including clinical stage of diabetes and medical treatment. The relationship between diabetes and depressive symptoms needs to be confirmed in future.

The strengths of this study include high participation rate, adjustment of potential confounding factors, and the use of a validated scale of depressive symptoms. Our study has also some limitations. First, because of its cross-sectional nature, any observed associations do not indicate a causal relationship. In a 7-year follow-up study [22], metabolic syndrome at baseline predicted increased risk of anxiety, suggesting that metabolic syndrome might increase the risk of depressive symptoms, rather than vice versa. Second, the number of subjects may not be sufficiently large to detect a modest association. Third, because we have no data for waist circumference, BMI was used.

In conclusion, the results of our study on Japanese employees does not support the hypothesis that metabolic syndrome is associated with depressive symptoms. An increased prevalence of a severe depressive state among men with fasting hyperglycemia requires confirmation.

Acknowledgments The authors thank Tamami Hatano, Akihiko Tanaka, and Yuko Ejima (Kyushu University); Mio Ozawa (Fukuoka Women's University); Akiko Hayashi and Kie Nagao (International Medical Center of Japan) for their help in data collection. This study was supported by a Grant-in-Aid for Scientific Research (C) (18590601) and (B) (21390213) from the Japan Society for the Promotion of Science.

Conflict of interest The authors declare no conflict of interest. 


\section{References}

1. Lakka HM, Laaksonen DE, Lakka TA, Niskanen LK, Kumpusalo $\mathrm{E}$, Tuomilehto $\mathrm{J}$, et al. The metabolic syndrome and total and cardiovascular disease mortality in middle-aged men. JAMA. 2002;288:2709-16.

2. Laaksonen DE, Lakka HM, Niskanen LK, Kaplan GA, Salonen JT, Lakka TA. Metabolic syndrome and development of diabetes mellitus: application and validation of recently suggested definitions of the metabolic syndrome in a prospective cohort study. Am J Epidemiol. 2002;156:1070-7.

3. Alberti KG, Eckel RH, Grundy SM, Zimmet PZ, Cleeman JI, Donato KA, et al. Harmonizing the metabolic syndrome: a joint interim statement of the International Diabetes Federation Task Force on Epidemiology and Prevention; National Heart, Lung, and Blood Institute; American Heart Association; World Heart Federation; International Atherosclerosis Society; and International Association for the Study of Obesity. Circulation. 2009; 120:1640-5.

4. Raikkonen K, Keltikangas-Jarvinen L, Adlercreutz H, Hautanen A. Psychosocial stress and the insulin resistance syndrome. Metabolism. 1996;45:1533-8.

5. Raikkonen K, Matthews KA, Kuller LH. Trajectory of psychological risk and incident hypertension in middle-aged women. Hypertension. 2001;38:798-802.

6. Weber-Hamann B, Hentschel F, Kniest A, Deuschle M, Colla M, Lederbogen $\mathrm{F}$, et al. Hypercortisolemic depression is associated with increased intra-abdominal fat. Psychosom Med. 2002;64: 274-7.

7. Kinder LS, Carnethon MR, Palaniappan LP, King AC, Fortmann SP. Depression and the metabolic syndrome in young adults: findings from the Third National Health and Nutrition Examination Survey. Psychosom Med. 2004;66:316-22.

8. Takeuchi T, Nakao M, Nomura K, Yano E. Association of metabolic syndrome with depression and anxiety in Japanese men. Diabetes Metab. 2009;35:32-6.

9. Akbaraly TN, Kivimaki M, Brunner EJ, Chandola T, Marmot MG, Singh-Manoux A, et al. Association between metabolic syndrome and depressive symptoms in middle-aged adults: results from the Whitehall II study. Diabetes Care. 2009;32: 499-504.

10. Takeuchi T, Nakao M, Nomura $K$, Inoue $M$, Tsurugano $S$, Shinozaki Y, et al. Association of the metabolic syndrome with depression and anxiety in Japanese men: a 1-year cohort study. Diabetes Metab Res Rev. 2009;25:762-7.

11. Herva A, Rasanen P, Miettunen J, Timonen M, Laksy K, Veijola $\mathrm{J}$, et al. Co-occurrence of metabolic syndrome with depression and anxiety in young adults: the Northern Finland 1966 Birth Cohort Study. Psychosom Med. 2006;68:213-6.

12. Hildrum B, Mykletun A, Midthjell K, Ismail K, Dahl AA. No association of depression and anxiety with the metabolic syndrome: the Norwegian HUNT study. Acta Psychiatr Scand. 2009;120:14-22.

13. Murakami K, Mizoue T, Sasaki S, Ohta M, Sato M, Matsushita Y, et al. Dietary intake of folate, other B vitamins, and omega-3 polyunsaturated fatty acids in relation to depressive symptoms in Japanese adults. Nutrition. 2008;24:140-7.

14. Grundy SM, Cleeman JI, Daniels SR, Donato KA, Eckel RH, Franklin BA, et al. Diagnosis and management of the metabolic syndrome: an American Heart Association/National Heart, Lung, and Blood Institute Scientific Statement. Circulation. 2005;112: 2735-52.

15. Dwimartutie N, Setiati S, Oemardi M. The correlation between body fat distribution and insulin resistance in elderly. Acta Med Indones. 2010;42:66-73.
16. Executive Summary of the Third Report of the National Cholesterol Education Program (NCEP) Expert Panel on Detection, Evaluation, and Treatment of High Blood Cholesterol in Adults (Adult Treatment Panel III). JAMA. 2001;285:2486-97.

17. Shima S, Shikano T, Kitamura T, Asai M. Atatashii yokuutsusei jiko hyouka shakudo ni tsuite (new self-rating scale for depression) (in Japanese). Clin Psychiatry. 1985;27:717-23.

18. Radloff L. The CES_D scale: a self-report depression scale for research in the general population. Appl Psychol Meas. 1977;1: 385-401.

19. Ohta M, Mizoue T, Mishima N, Ikeda M. Effect of the physical activities in leisure time and commuting to work on mental health. J Occup Health. 2007;49:46-52.

20. Nakata A, Takahashi M, Ikeda T, Hojou M, Nigam JA, Swanson NG. Active and passive smoking and depression among Japanese workers. Prev Med. 2008;46:451-6.

21. Skilton MR, Moulin P, Terra JL, Bonnet F. Associations between anxiety, depression, and the metabolic syndrome. Biol Psychiatry. 2007;62:1251-7.

22. McCaffery JM, Niaura R, Todaro JF, Swan GE, Carmelli D. Depressive symptoms and metabolic risk in adult male twins enrolled in the National Heart, Lung, and Blood Institute twin study. Psychosom Med. 2003;65:490-7.

23. Roriz-Cruz M, Rosset I, Wada T, Sakagami T, Ishine M, RorizFilho JS, et al. Stroke-independent association between metabolic syndrome and functional dependence, depression, and low quality of life in elderly community-dwelling Brazilian people. J Am Geriatr Soc. 2007;55:374-82.

24. Gil K, Radzillowicz P, Zdrojewski T, Pakalska-Korcala A, Chwojnicki K, Piwonski J, et al. Relationship between the prevalence of depressive symptoms and metabolic syndrome. Results of the SOPKARD project. Kardiol Pol. 2006;64:464-9.

25. Vogelzangs N, Beekman AT, Kritchevsky SB, Newman AB, Pahor M, Yaffe K, et al. Psychosocial risk factors and the metabolic syndrome in elderly persons: findings from the Health, Aging and Body Composition Study. J Gerontol A Biol Sci Med Sci. 2007;62:563-9.

26. Raikkonen K, Matthews KA, Kuller LH. Depressive symptoms and stressful life events predict metabolic syndrome among middle-aged women: a comparison of World Health Organization, Adult Treatment Panel III, and International Diabetes Foundation definitions. Diabetes Care. 2007;30:872-7.

27. Dunbar JA, Reddy P, Davis-Lameloise N, Philpot B, Laatikainen T, Kilkkinen A, et al. Depression: an important comorbidity with metabolic syndrome in a general population. Diabetes Care. 2008;31:2368-73.

28. Maraldi C, Volpato S, Penninx BW, Yaffe K, Simonsick EM, Strotmeyer ES, et al. Diabetes mellitus, glycemic control, and incident depressive symptoms among 70- to 79-year-old persons: the health, aging, and body composition study. Arch Intern Med. 2007; 167:1137-44.

29. de Jonge P, Roy JF, Saz P, Marcos G, Lobo A. Prevalent and incident depression in community-dwelling elderly persons with diabetes mellitus: results from the ZARADEMP project. Diabetologia. 2006;49:2627-33.

30. Anderson RJ, Freedland KE, Clouse RE, Lustman PJ. The prevalence of comorbid depression in adults with diabetes: a meta-analysis. Diabetes Care. 2001;24:1069-78.

31. Brown LC, Majumdar SR, Newman SC, Johnson JA. Type 2 diabetes does not increase risk of depression. Can Med Assoc J. 2006;175:42-6.

32. Golden SH, Lazo M, Carnethon M, Bertoni AG, Schreiner PJ, Diez Roux AV, et al. Examining a bidirectional association between depressive symptoms and diabetes. JAMA. 2008; 299:2751-9. 